\title{
28 Research Square \\ Factors Influencing Medical Students' Attitudes Towards Substance Use During Pregnancy
}

\author{
Lou Richelle ( $\square$ lou.richelle@ulb.be ) \\ Université Libre de Bruxelles \\ Michèle Dramaix-Wilmet \\ Université Libre de Bruxelles \\ Michel Roland \\ Université Libre de Bruxelles \\ Nadine Kacenelenbogen \\ Université Libre de Bruxelles
}

\section{Research Article}

Keywords: substance use, pregnancy, medical students, attitudes

Posted Date: June 4th, 2021

DOI: https://doi.org/10.21203/rs.3.rs-576558/v1

License: (9) This work is licensed under a Creative Commons Attribution 4.0 International License.

Read Full License 


\section{Title: Factors influencing medical students' attitudes towards}

\section{substance use during pregnancy}

Lou Richelle ${ }^{1}$, Michèle Dramaix-Wilmet ${ }^{2}$, Michel Roland ${ }^{1}$, Nadine Kacenelenbogen ${ }^{1}$

${ }^{1}$ Department of General Medicine

Université Libre de Bruxelles

Route de Lennik 808, CP 6121070 Brussels

Belgium

${ }^{2}$ Department of Epidemiology and Biostatistics

School of Public Health

Université Libre de Bruxelles

Route de Lennik 808, CP 5911070 Brussels

Belgium

\section{Corresponding author:}

Lou Richelle

Department of General Medicine

Université Libre de Bruxelles

Route de Lennik 808, CP 6121070 Brussels

Belgium

E-mail: lou.richelle@ulb.be

Tel: 003225556167 


\begin{abstract}
Background : Many stigmas exist regarding people with substance use disorder especially among pregnant women, preventing optimal accessibility and quality of care. In this survey, we investigated attitudes of final year medical students regarding substance use during pregnancy and identified the factors that influence these attitudes.
\end{abstract}

Methods : This cross-sectional study was conducted in 2019 and 2020 in Belgium using the short version of the "Substance Abuse Attitude Survey" questionnaire. We focused on two items regarding punishment of substance use during pregnancy. We analysed the concordance between these two, their correlation with other items (e.g stereotyping, morality, forced withdrawal, low treatment optimism) and the association between respondents' agreement on punishment and their sociodemographic data.

Results : The response rate was $65.2 \%$ (370/567 online and face-to face questionnaires). $19.2 \%$ of respondents were in favour of punishment for alcohol use $(\mathrm{n}=353)$ and $15.1 \%$ for drug use $(n=356)$ during pregnancy. The agreement analysis between the two items showed that $14.3 \%$ of students were in favour of punishing both pregnant women who use drugs and those using alcohol. Respondents tended to be more in favour of punishment if they were male students, older, if they had a lower mother's education level or had no personal or family history of substance use. Attitudes appeared to be more punitive among students with limited contact with people with substance use disorder (i.e. none or limited to hospital). Students intending to specialise in internal medicine were more in favour of punishment of women whereas none of those intending to specialise in psychiatry were in favour. 
Conclusion : Our study shows that about $20 \%$ of surveyed medical students favoured punishing substance-using pregnant women. Awareness and training work seems to be necessary to ensure adequate care and support for this already vulnerable population.

Keywords : substance use, pregnancy, medical students, attitudes 


\section{Introduction}

Thirty-five million people worldwide have substance use disorders (SUD) (1). This is a major and constantly evolving public health concern. Pregnant women are not spared from these disorders and their susceptibility is increasing in certain regions (2,3). People who use drugs (PWUD) are stigmatised in numerous and various ways $(4,5)$, and this is amplified among pregnant women who use substances $(6,7)$. This is a complex phenomenon which can be divided into two categories: individual (self) stigma and societal stigma. Self-stigma is defined here as: "the harmful effect that occurs when a person with SUD internalises stereotypes leading to a kind of self-discrimination" (8). Societal stigmas, on the other hand, are stereotypes, prejudices and discriminations integrated by a community (called social or public stigmas) or by institutions (structural stigmas) (9).

Healthcare professionals are not spared from the tendency towards societal stigmatisation of others creating the risk of promoting punitive attitudes rather than support and care for drug users $(10,11)$.

Punitive attitudes constitute significant barriers to accessibility and quality of care for these pregnant women with SUD. Indeed, these women are already often on the margins of healthcare systems because of various coexistent vulnerabilities (precariousness, intra-family violence, history of sexual abuse, post-traumatic shock disorder, etc.) and other exacerbated stigmas among this population $(6,7)$. These attitudes will increase their risk of marginalisation and exclusion from the healthcare system. Negative attitudes delay these women's recourse to care for fear of judgment $(6,7,12)$ and the socio-legal consequences for them and their progeny such as incarceration, forced treatment, loss of custody of the child etc. $(6,12,13)$. Substance using women of childbearing age, like all women, may or may not desire to have children. If and when they do present in pregnancy the healthcare system should be able to 
respond quickly and accompany them adequately. Not least because this can be a moment for motivation towards change. Such opportunities should be recognised, supported and followed through $(6,7,14)$. The period is nevertheless marked by psychological fragility and an increased risk of domestic violence $(6,7,12)$.

The question of how medical students and doctors view the punishment of pregnant women has been little explored in the studies, as has the understanding of what can influence such behaviour amongst care providers. Assessing the importance of stigma and attitudes among future doctors seems essential towards working on improving the quality of care for this target group. Stigma tends to crystallise and strengthen over time and practice $(11,15)$, so it is interesting to take stock at a pivotal moment in a future doctors' practice. Assessment of their behaviour might allow for positive interventions.

In addition, a new law in Belgium seeking to amend the Civil Code with a view to introducing prenatal legal protection (DOC 55 1029/001) was submitted to the Chamber on 13 February 2020. This law aims to protect the foetus-in-utero of mothers who are substance abusers and who suffer from psychiatric disorders. The means to protect the foetus could include guardianship, imposed hospitalisation for withdrawal and obligatory caesarean sections. All this background prompted us to investigate the attitudes of final year medical students (representing future generations of doctors) regarding substance use during pregnancy and analyse what factors influenced their attitudes. 


\section{Methods}

We used the short version (16) of the Substance Abuse Attitude Survey (Chappel et al., 1985) (17) a questionnaire validated in the international literature to conduct a cross-sectional study at the Faculty of Medicine of the Université Libre de Bruxelles in 2019 and 2020.

The short questionnaire originally consisted of 25 items. With a committee of experts, we readapted the questionnaire to the Belgian context. We removed questions on marijuana experimentation among young people and on Alcoholics Anonymous, elements less present in Belgium than in the USA. We added a question about paramedical professionals who are much more involved than paraprofessional counselors in our setting. We decided to split the questions on alcohol and drugs in order to be able to assess whether there were different attitudes according to the products consumed. This led to a questionnaire with 29 items (see Appendix) of good reliability (Cronbach s Alpha at 0.77). Our considerations were informed by the knowledge that perceptions between what constitute illegal and legal drugs may differ. Indeed, a general perception of the Belgian population is that the term "drugs" refers de facto to illegal drugs. This difference was highlighted in studies among Belgian doctors $(18,19)$. In addition, we sought to ensure the transcultural validity of the questionnaire by using bilateral translation and pre-testing the questionnaire amongst doctors with different experiences and amongst lay people as well.

We left the possibility of answering the questionnaire as originally planned, i.e. respondents could position themselves on a 5 point Likert scale ("strongly disagree" to "strongly agree"). We felt it was important to give respondents the option of a "tend to agree/disagree" opinion or to be undecided rather than being forced into a trenchant opinion on contentious items. 
In order to assess the socio-demographic dimensions of our participants, we included various questions based on previous studies (20-22):

1. Socio-demographic type (gender, age, origin)

2. Personal experience (respondent's personal use or the problematic use by someone in their own social circle/entourage)

3. Orientation towards a particular medical specialty

4. Previous personal professional experience (for example encounters with SUD people)

5. Respondent's personal health (we wanted to assess whether the perception of one's own health has an effect on the way in which dependent people are perceived). The hypothesis was that a person who considered himself to be in poorer health would potentially be more empathetic towards patients with this chronic disease. We constructed our question on the basis of the WHO SF-36 quality of life questionnaire (23).

The questionnaire was presented to 567 final year medical students in two consecutive years (2019 and 2020). This questionnaire was administered face-to-face to final year medical students in 2019 and online in 2020 given the context of the Sars-Cov-2 crisis.

A total of 370 students responded to the questionnaire with a response rate of $82 \%$ in 2019 and $47.3 \%$ in 2020 (overall response rate of $65.2 \%$ ). 32 students filled in the questionnaire during registration for optional training on addiction theory and management.

We considered as invalid questionnaires with less than 10 answers, those with answers for only one of the two substances and those where the socio-demographic data were not filled in. 
356 completed questionnaires for drugs and 353 for alcohol (350 when the two are crossed) were retained.

For the analysis of the data, we focused on two items in the questionnaire which stated that pregnant women who use substances should be punished with this following formulation: "pregnant women who use drugs (Q18)/alcohol (Q29) should be punished". The variables were described using frequencies and percentages. The Kappa coefficient was used to measure the agreement between the 2 items. The statistical tests used to compare the proportions were the $\mathrm{Chi}^{2}$ and Fisher's Exact test when the $\mathrm{Chi}^{2}$ was not valid. To analyse the correlation between items coded on a 5 option Likert scale, the Spearman non-parametric correlation coefficient $\left(\mathrm{r}_{\mathrm{s}}\right)$ was used. STATA SE V16.1 software was used for all analyses and the significance level was set at $5 \%$.

The research protocol was approved by the local ethics committee (ERASME hospital; medical board's approval number: OM 021) on February 25, 2019, ref: P2019/156. An informed consent was obtained from all participants who filled out and returned the questionnaire.

\section{Results}

\section{$\underline{\text { Overall comment on respondents' views on punishment }}$}

Of the respondents, $15.1 \%$ agreed that women who use drugs should be punished. $19.2 \%$ of respondents believed those using alcohol should be punished. In the distribution of responses, the highest percentage response was those who "disagree about punishment", whether it was for alcohol or drugs. In both cases, there was a relatively large percentage of « undecided », more pronounced for drugs than for alcohol (22.5\% vs. 19.6\%) shown in Figure 1. 


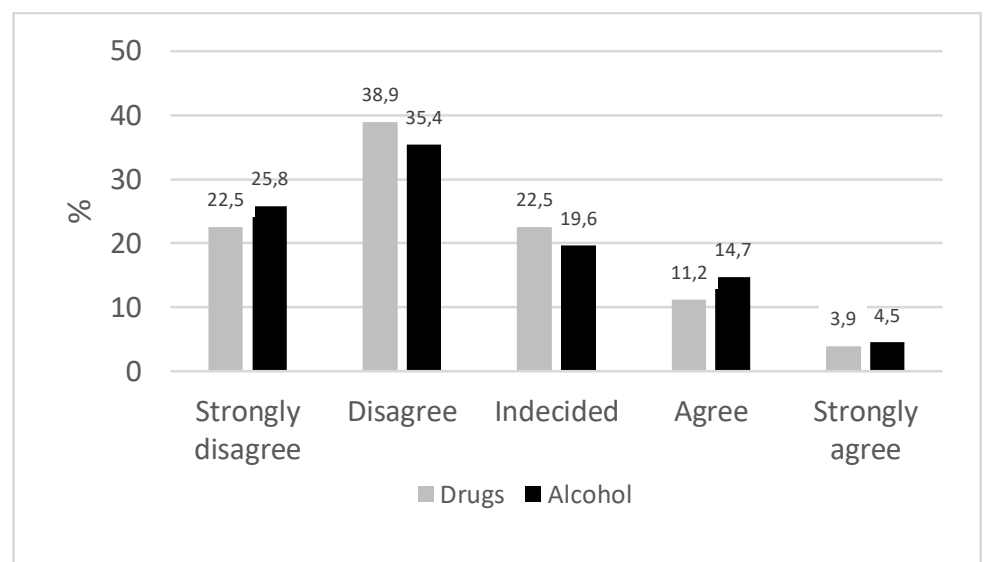

Figure 1: Distribution (\%) of responses to questions on punishment if a pregnant woman uses drugs or alcohol.

The concordance analysis of responses to the two items is shown in Table 1.

Table 1. Punishment for pregnant women using drugs or alcohol

\begin{tabular}{lccc}
\hline \multicolumn{3}{c}{ Alcohol } \\
\hline Drugs & $\begin{array}{c}\text { Disagree } \\
\mathrm{n}(\%)\end{array}$ & $\begin{array}{c}\text { Undecided } \\
\mathrm{n}(\%)\end{array}$ & $\begin{array}{c}\text { Agree } \\
\mathrm{n}(\%)\end{array}$ \\
\hline Disagree & $\mathbf{2 0 0 ( \mathbf { 5 7 . 1 } )}$ & $10(2.9)$ & $6(1.7)$ \\
Undecided & $12(3.4)$ & $\mathbf{5 7}(\mathbf{1 6 . 3})$ & $11(3.1)$ \\
Agree & $3(0.9)$ & $1(0.3)$ & $\mathbf{5 0}(\mathbf{1 4 . 3})$ \\
\hline calculated per cell on the total $(\mathrm{n}=350)$ - in bold: observed concordance
\end{tabular}

Overall, $14.3 \%$ of students were in favour of punishing pregnant women both for drug use and for alcohol use. The observed proportion of agreement was $87.7 \%$ and the Kappa coefficient, equal to 0.775 , showed good agreement.

\section{$\underline{\text { Position on punishment and personal characteristics of the respondents }}$}

Table 2 shows that certain trends emerged when analysing the associations between the characteristics of the respondents and their responses to items relating to the punishment of pregnant women who use drugs or alcohol. Given the small size of some groups, hardly any of these associations reached statistical significance. A higher percentage of respondents in favour of punishing pregnant women was found among: older people, men, students with 
mothers with lower levels of education, people who did not use drugs or who did not have substance use disorders in their entourage. There was a statistically significant association between registration or not in optional theoretical training on addiction management (offered by the Department of General Medicine of our faculty) and the opinion on punishment for drug or alcohol use. The percentage of those in favour of punishment was significantly higher among those not enrolled in the training. 
Table 2. Association between respondents' personal characteristics and agreement on punishment

\begin{tabular}{|c|c|c|c|c|c|c|c|c|}
\hline & \multicolumn{4}{|c|}{ Drugs } & \multicolumn{4}{|c|}{ Alcohol } \\
\hline & $\begin{array}{c}\text { Disagree } \\
\mathrm{n}(\%)\end{array}$ & $\begin{array}{c}\text { Undecide } \\
\mathrm{d} \\
\mathrm{n}(\%)\end{array}$ & $\begin{array}{l}\text { Agree } \\
\mathrm{n}(\%)\end{array}$ & $\mathrm{P}^{\mathrm{a}}$ & $\begin{array}{c}\text { Disagree } \\
\text { n }(\%)\end{array}$ & $\begin{array}{c}\text { Undecide } \\
\mathrm{d} \\
\mathrm{n}(\%)\end{array}$ & $\begin{array}{c}\text { Agree } \\
\mathrm{n}(\%)\end{array}$ & $\mathrm{P}^{\mathrm{a}}$ \\
\hline Age (years) & & & & 0,378 & & & & 0,219 \\
\hline$<25$ & $121(63.0)$ & $41(21.4)$ & $30(15.6)$ & & $121(63.0)$ & $36(18.8)$ & $35(18.2)$ & \\
\hline $25-29$ & $86(63.2)$ & $33(24.3)$ & $17(12.5)$ & & $81(60.9)$ & $29(21.8)$ & $13(17.3)$ & \\
\hline 30 et + & $10(50.0)$ & $4(20.0)$ & $6(30.0)$ & & $9(45.0)$ & $3(15.0)$ & $8(40.0)$ & \\
\hline Gender & & & & 0,107 & & & & 0,122 \\
\hline $\mathrm{F}$ & $155(65.7)$ & $51(21.6)$ & $30(12.7)$ & & $151(64.5)$ & $44(18.8)$ & $39(16.7)$ & \\
\hline $\mathrm{M}$ & $63(55.3)$ & $28(24.6)$ & $23(20.2)$ & & $61(54.0)$ & $24(21.2)$ & $28(24.8)$ & \\
\hline Mother s education ${ }^{\mathrm{b}}$ & & & & 0,217 & & & & 0,115 \\
\hline Low & $13(46.4)$ & $7(25.0)$ & $8(28.6)$ & & $12(42.9)$ & $8(28.6)$ & $8(28.6)$ & \\
\hline Middle & $39(63.9)$ & $12(19.7)$ & $10(16.4)$ & & $39(65.0)$ & $7(11.7)$ & $14(23.3)$ & \\
\hline High & $162(63.5)$ & $60(23.5)$ & $33(12.9)$ & & $157(62.1)$ & $53(21.0)$ & $43(17.0)$ & \\
\hline Origin (subjects-parents) ${ }^{\mathrm{c}}$ & & & & 0,843 & & & & 0,541 \\
\hline Belgium & $97(63.8)$ & $35(23.0)$ & $20(13.2)$ & & $101(66.9)$ & $25(16.6)$ & $25(16.6)$ & \\
\hline Mix BE & $31(57.4)$ & $14(25.9)$ & $9(16.7)$ & & $31(58.5)$ & $12(22.6)$ & $10(18.9)$ & \\
\hline Mix BNE & $19(57.6)$ & $7(21.2)$ & $7(21.2)$ & & $15(46.9)$ & $7(21.9)$ & $10(31.3)$ & \\
\hline Europe & $37(58.7)$ & $14(22.2)$ & $12(19.1)$ & & $35(55.6)$ & $13(20.6)$ & $15(23.8)$ & \\
\hline Outside Europe & $29(70.7)$ & $2(19.5)$ & $4(9.8)$ & & $26(63.4)$ & $8(19.5)$ & $7(17.1)$ & \\
\hline Drug use & & & & 0,133 & & & & 0,231 \\
\hline None & $106(56.7)$ & $47(25.1)$ & 34 (18.2) & & $105(56.5)$ & $39(21.0)$ & $42(22.6)$ & \\
\hline Cannabis & $80(71.4)$ & $21(18.8)$ & $11(9.8)$ & & $78(69.6)$ & $18(16.1)$ & $16(14.3)$ & \\
\hline Multiple & $28(59.6)$ & $11(23.4)$ & $8(17.0)$ & & $26(57.8)$ & $10(22.2)$ & $9(20.0)$ & \\
\hline Entourage drug use & & & & 0,568 & & & & 0,464 \\
\hline None & $73(57.9)$ & $28(22.2)$ & $25(19.8)$ & & $69(55.7)$ & $25(20.2)$ & $30(24.2)$ & \\
\hline Alcohol & $27(64.3)$ & $10(23.8)$ & $5(11.9)$ & & $26(63.4)$ & $10(24.4)$ & $5(12.2)$ & \\
\hline Cannabis & $11(57.9)$ & $7(36.8)$ & $1(5.3)$ & & $9(50.0)$ & $6(33.3)$ & $3(16.7)$ & \\
\hline Alcohol-cannabis & $43(70.5)$ & $11(18.0)$ & $7(11.5)$ & & $42(67.7)$ & $9(14.5)$ & $11(17.7)$ & \\
\hline Others drugs & $63(62.4)$ & $23(22.8)$ & $15(14.9)$ & & $65(64.4)$ & $18(17.8)$ & $18(17.8)$ & \\
\hline Health perception & & & & 0,475 & & & & 0,420 \\
\hline Excellent & $20(52.6)$ & $12(31.6)$ & $6(15.8)$ & & $21(55.3)$ & $11(29.0)$ & $6(15.8)$ & \\
\hline Very good & $36(70.6)$ & $9(17.7)$ & $6(11.8)$ & & $36(70.6)$ & $8(15.7)$ & $7(13.7)$ & \\
\hline Good-Fair & $19(63.3)$ & $6(20.0)$ & $5(16.7)$ & & $17(56.7)$ & $6(20.0)$ & 7 (23.3) & \\
\hline $\begin{array}{l}\text { Addiction training } \\
\text { subscription }\end{array}$ & & & & 0,028 & & & & 0,023 \\
\hline No & $195(60.2)$ & 77 (23.8) & $52(16.1)$ & & $191(59.5)$ & $63(19.6)$ & 67 (20.9) & \\
\hline Yes & $27(84.3)$ & $3(9.4)$ & $2(6.3)$ & & $25(78.1)$ & $6(18.8)$ & $1(3.1)$ & \\
\hline
\end{tabular}

a: Fisher exact or $\mathrm{Chi}^{2}$. $:$ : Low $=$ no diploma to lower secondary, Middle $=$ from lower secondary to upper secondary, high $=$ higher education (high school, university, PhD). c: BE =Belgian and European; BNE = Belgian and non European

Effect of Choice of specialty and previous encounters with PWUD on responses

Higher percentages of students in favour of punishing pregnant drug users were observed for students going into internal medicine, gynaecology and other specialties. There were also relatively high percentages of undecided voters for students going into child or adult 
psychiatry, internal medicine and other specialisations, but also for future general practitioners. The percentage in favour of punishment was nil among psychiatrists (child and adult) followed by future paediatricians. The results were quite similar for alcohol as we can observe in Figure 2.
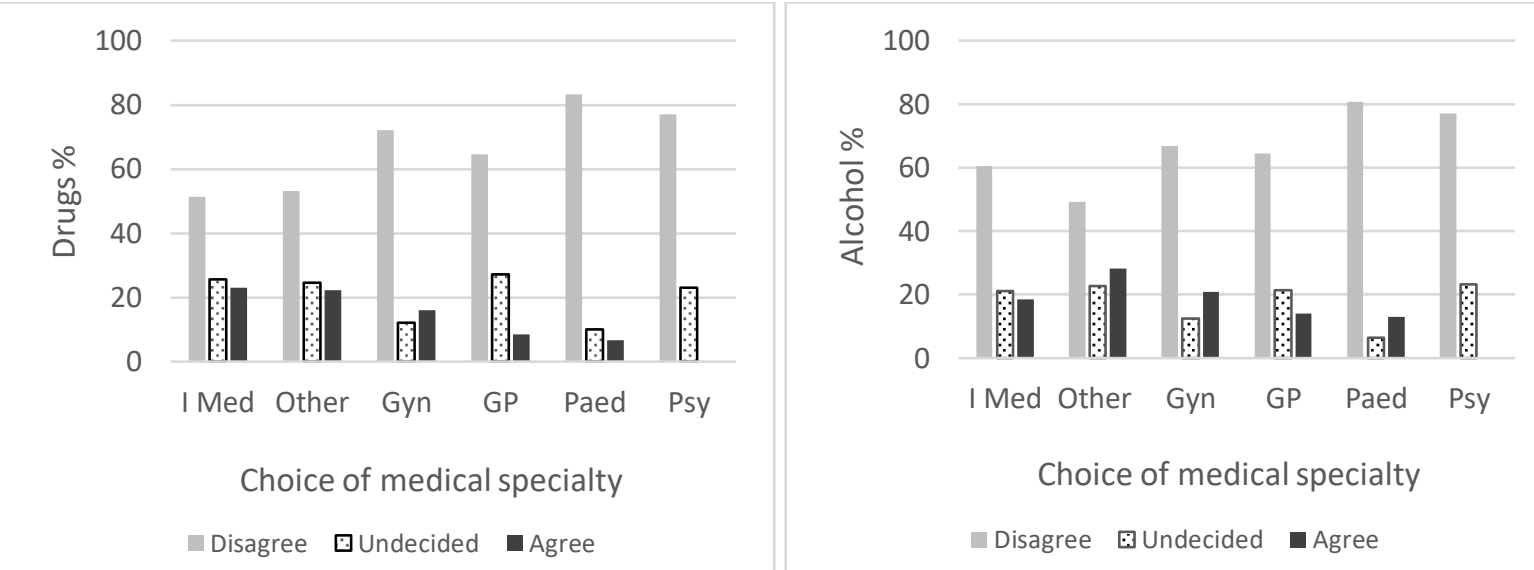

Figure 2 : distribution of responses to the question of punishment for pregnant women who use drugs (figure on the left; $\mathrm{p}=0.014$ ) or alcohol (figure on the right, $\mathrm{p}=0.033$ ) according to the medical specialty chosen. Choice of speciality: Internal Medicine (I Med), Other (others specialities), Gynaecology (Gyn), General Practice (GP), Paediatrics (Paed), Child and Adult Psychiatry (Psy).

Figure 3 shows that the percentage 'agreeing' with the punishment of pregnant women using drugs was higher among students who had no contact with drug users during internship followed closely by students who had contact in hospital internship only. It was nil among the 13 students who did a traineeship in a GP practice and low among those who had contact in specific centres for drug users. The observations were similar for punishment for alcohol consumption. We were particularly interested in contact with PWUD only in the emergency room, given that this is a special type of contact, as opposed to all hospital contacts, and we did not find any clear difference among those in favour of punishment (18.92\% vs.16.87\%). 


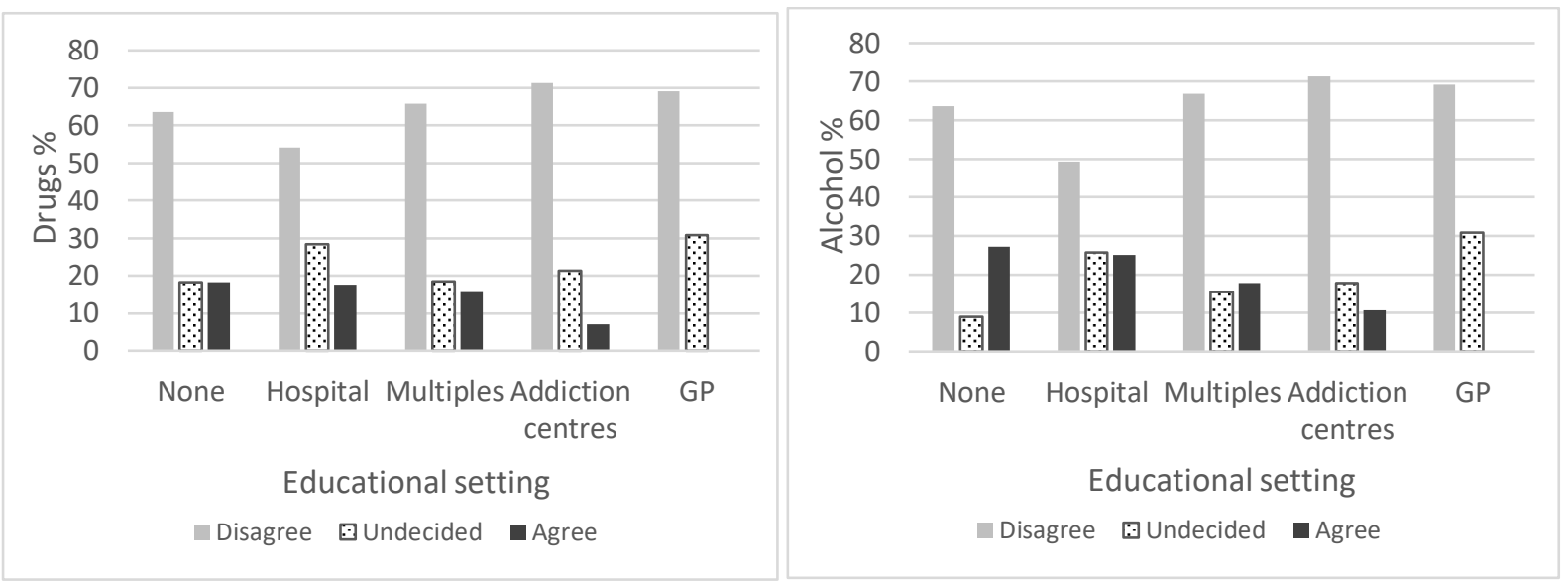

Figure 3 : distribution of responses to the question of punishment for pregnant women who use drugs (figure on the left, $\mathrm{p}=0.296$ ) or alcohol (figure on the right, $\mathrm{p}=0.031$ ) according to educational setting. $\mathrm{GP}=\mathrm{General}$ Practice.

We also looked for correlation between the question/response items relating to stereotypes, morality, forced withdrawal or low treatment optimism and the question/response items about punishment for pregnant women using drugs or alcohol. All the associations, except one, were statistically significant but these associations were weak $\left(\mathrm{r}_{\mathrm{s}}: 0.12\right.$ to 0.32$)$. These associations were slightly stronger for alcohol than for drugs.

We were also particularly interested in any association between items relating to pregnant women who use drugs and alcohol and the item about coercive pressure for those resistant to trying treatment (which is now included in the law); the three items were categorised as "disagree, undecided, agree". In both cases the associations were statistically significant $(\mathrm{p}<0.001)$ for both drugs and alcohol.

It was observed that $64.8 \%$ of respondents in favour of punishing pregnant women who use drugs did not agree with imposed hospitalisation. However, $88.7 \%$ of those who were not in favour of punishment did not agree with imposed hospitalisation. Of those who were undecided about punishment $73.8 \%$. were against imposed hospitalisation.

We also note that the percentage of students favouring punishment of pregnant women who use drugs was significantly higher than those in favour of treatment under coercive pressure ( $15.2 \%$ vs. $5.9 \%)$, as was the case with the percentage of those undecided about punishment 
and those in favour of coercive treatment (22.5\% vs. $12.4 \%$ respectively). The results for punishment for alcohol use were quite similar.

\section{Discussion}

Our study highlights some challenging findings, as there is evidence that negative attitudes can be a significant barrier to the care of women who use substances throughout the perinatal period, resulting in delayed care with detrimental health and social consequences for women and newborns. $(5-7,10,12)$. The punitive attitudes of the students in our study, although it is not clear what underpins them, seemed less pronounced than in the study by Abel et al. (24). This study showed that $52 \%$ of the doctors questioned were in favour of passing a law putting drugs or alcohol use during pregnancy in the category of "child abuse" with the aim of removing child custody from these mothers. We are a long way from this result, but we also know that negative attitudes tend to increase with age and clinical practice $(11,15,22)$. However, the literature reports that these attitudes are counterproductive for pregnant women who are consumers $(26,27)$. Indeed, studies highlight the link between punitive and reporting policies, resulting in fewer pregnant women taking substitution treatment and an increase in neonatal withdrawal syndromes (28). Punitive policies here are defined as policies by which substance use during pregnancy was criminalised, considered grounds for civil commitment, or considered child abuse or neglect; and reporting policies are defined as policies that mandated reporting of suspected prenatal substance use to relevant authorities.

The fact that the question of punishing pregnant women was asked as one of a series of other general items on PWUD drugs seems to be a strong element of the study, since the responses appeared to be fairly spontaneous and instinctive, hopefully avoiding social desirability bias. 


\section{$\underline{\text { Characteristics of the respondents }}$}

Firstly, our results confirm our hypothesis about the difference in perception between the use of alcohol and other drugs by medical students. In our study, the willingness to punish pregnant women who use alcohol seems more important than for other drugs. We believe that these attitudes are more negative because the students are more familiar with this product and know more about its effects on the woman and the newborn baby. Being familiar with an issue is generally associated with less stigmatising in studies $(21,22,29)$, but in this context it is a question of considering not only the pregnant women who use drugs and their health, but also the health of the unborn child. It is also important to note that the use of substances other than alcohol by pregnant women is very little dealt with in the university curriculum, with the main focus being on foetal alcohol syndrome. This could partly explain the large number of undecided voters, which is more marked for drugs than for alcohol (23.5\% vs. $19.6 \%)$. The punitive approach seems to be influenced by certain characteristics of the respondents. Some, but not all, are already identified in the literature.

Considering that in our sample we are interested in medical students, the majority of our respondents are less than 30 years of age. We can see, however, that there is a tendency to be more punitive towards pregnant women among older respondents. This trend is in line with the literature which shows that stereotypical attitudes increase with age $(11,15,22)$. We also note that gender seems to have an influence on attitudes with more negativity amongst men than women. Studies are divided on the impact of gender on attitudes in relation to drug users. Attitudes seem to differ according to the substance and familiarity with it (8, $22,25,29)$. We did not find any studies linking the gender of healthcare professionals and their attitudes in relation to pregnant women drug users. The fact that in our study, the female gender tends to have a less repressive view could be explained by a phenomenon of identification and projection. It is therefore necessary to be able to qualify other studies 
concerning attitudes towards PWUD, who are predominantly male (1). It does not seem surprising to us that male respondents here have more negative attitudes towards pregnant female drug users. These women are supposed to be future mothers and to run the household.

The question of the cultural origin of the students also arises but does not seem to have any influence in our study. The literature is more mixed on this subject $(8,20,25)$.

We find no equivalent in the literature to the tendency that students from a less educated environment are more judgmental of drug users than those from a higher educated environment. One study highlights less stigma among people with low incomes compared to opiate addiction, which they explain by greater familiarity with opiates in these environments $(25)$.

As regards the choice of future medical specialty, we find few elements of comparison in the literature, since the studies were mainly interested in only certain types of specialisation. There are, however, studies which show that anaesthetists and emergency doctors have the most negative attitudes $(10,11,22,30)$. Psychiatrists have less of a negative attitude than general practitioners (21). This is confirmed in our study. Once again, these are attitudes which are concerned with drug users and not with pregnant women who use drugs. Unexpectedly, future paediatricians have less repressive attitudes than the future gynaecologists in our study.

With regard to encounters with, or experience of, the SUD problem and in what setting, our sample shows that students who have not been in contact with drug users, or who have only been in contact with them in hospital, have more punitive attitudes. Those who have been in 
contact with drug users in various places of work experience, both in hospital and on an outpatient basis have less punitive attitudes. It is interesting to note that it is contact with drug users in general practice medicine which seems to have the most favourable impact on the participants' perceptions, followed by contact in centres for people with SUD. The fact that patients who consult in these centres are often more precarious, marginalised, and in a poorer overall state of health may perhaps influence the medical student. Women with SUD in these centres are often in a worse overall health condition than the average encountered in general practice. Contacts in the emergency room are often situations where the care relationship can be undermined. The contact is acute, with patients regularly presenting and returning in psychosomatic distress (31). It seemed important to objectify this point in our study. Unfortunately, as our sample of future emergency physicians was too small $(n=11)$, we could not draw any conclusions. Nor were we able to find any significant difference between contact in the emergency department only versus in the hospital environment in general.

Personal history of substance use or problematic substance use in one's own entourage seemed to have a rather favourable impact on the representations. This is in line with the findings of the studies $(10,18,22)$.

\section{$\underline{\text { Possible interventions or actions }}$}

We cannot have an impact on the socio-demographic characteristics and personal experiences of medical students, but we can work on initial medical training.

Indeed, studies show $(15,32,33)$ that having educational programs and contact with patients in specialised services can have a positive impact on students' development. Studies show that curriculum based on contact and moreover repeated contact, preferably in suitable environments, are favourable. Likewise contact with pregnant women users of gynaecological 
services is more favourable where adequate support structures and services have already been set up $(15,34,35)$.

Negative attitudes of caregivers towards women consumers are a major obstacle to the quality of care. Such attitudes also have a negative impact on patients' feelings of empowerment and optimism about treatment and recovery $(5,7)$. A less judgmental rather than punitive attitude towards care is therefore beneficial at all levels for women and their newborns.

According to the literature appropriate care is also efficient. Opiate-related disorders are considered treatable chronic diseases in pregnant women, especially when they are detected early and receive comprehensive and adequate care (36). Integrative models accompanying women in a multidisciplinary manner have shown positive health and social benefits for the mother and her newborn $(14,36,37)$.

Specialised and multidisciplinary arrangements for these pregnant women consumers exist in Belgium but are still largely insufficient. This fact and a lack of knowledge and positive experiences may in part explain these negative attitudes.

However, these results should be interpreted with certain reservations. In the questionnaire, we left to respondents the possibility of expressing a leaning to a point of view rather than positioning themselves in a clear-cut definitive manner upon contentious issues which may give rise to debate and invite nuanced answers (cf. odd Likert scale) This option might lead to a large percentage of undecided responses which limits the statistical significance of the results.

Given the sensitive subject and the fact that the questions here were very brief and that the punishment was not clearly defined, it would be interesting to go further and explore this theme in more detail by conducting a qualitative study on the topic. It would also be interesting to compare the responses of students entering the medical curriculum with those 
leaving and also responses of older doctors to be able to assess the influence of the curriculum and then later the effects of professional practice on attitudes.

\section{Conclusion}

In our study, almost a sixth of students (14.3\%) were in favour of punishing both pregnant women who use alcohol and those who use drugs. This result is higher for women using alcohol (19.2\%). The scientific literature reports that this attitude is counterproductive and harmful for mothers and unborn children. Our study also notes that certain types of contact with drug users reduce these negative attitudes, such as contact in appropriate clinics and contact during internship with a general practitioner. These positive contacts should therefore be encouraged in the future. It is also important to develop increased awareness of the issue itself, along with the various influences and career attitudes that can arise during training via the university curriculum to promote a vision and ethos of support rather than punishment.

\section{List of abbreviations}

SUD: Substance Use Disorder

PWUD: people who use drug

\section{Declarations}

\section{- Ethics approval and consent for participate}

The research protocol was approved by the local ethics committee (ERASME hospital; medical board's approval number: OM 021) on February 25, 2019, ref: P2019/156. All 
methods were carried out in accordance with relevant guidelines and regulations. An informed consent was obtained from all participants who filled out and returned the questionnaire.

- Consent for publication

Not applicable

- Availability of data and materials

The dataset used and/or analyzed during the current study are available from the corresponding author on reasonable request.

\section{- $\quad$ Competing interests}

No competing interest are declared.

- $\quad$ Funding

No funding.

- $\quad$ Authors' contributions

LR contributed to the conception and design of the study, she proceeded to the data collection. She wrote the original draft of the manuscript. She was involved in the analysis and interpretation of the data. MDW had the lead in the analysis and interpretation of the data and was a major contributor in revising the manuscript. MR co-supervised the study and the content. NK intellectually contributed to the study process. All authors read, commented and approved the final manuscript. 
- $\quad$ Acknowledgements

We would like to thank Dr Camille Chatelle for her input on the manuscript, Dr John Baldwin for the English proofreading and the Committee of Experts who helped to build the new questionnaire.

\section{References}

1. Vereinte Nationen, Büro für Drogenkontrolle und Verbrechensbekämpfung. World drug report 2020. 2020. https://wdr.unodc.org/wdr2020/index.html. Accessed 02 Apr 2021.

2. Goodman D, Whalen B, Hodder LC. It's Time to Support, Rather Than Punish, Pregnant Women With Substance Use Disorder. JAMA Netw Open Internet. 2019;(v 13;2(11):e1914135). doi:10.1001/jamanetworkopen.2019.14135.

3. Haight SCKJ, Ko JY, Tong VT, Bohm MK, Callaghan WM. Opioid use disorder documented at delivery hospitalization: United States, 1999-2014. MMWR Morb Mortal Wkly Rep. 2018;67(31):845-9. doi: 10.15585/mmwr.mm6731a1.

4. Barry CL, McGinty EE, Pescosolido BA, Goldman HH. Stigma, discrimination, treatment effectiveness, and policy: public views about drug addiction and mental illness. Psychiatr Serv Wash DC. oct 2014;65(10):1269-72. doi: 10.1176/appi.ps.201400140.

5. Crapanzano KA, Hammarlund R, Ahmad B, Hunsinger N, Kullar R. The association between perceived stigma and substance use disorder treatment outcomes: a review. Subst Abuse Rehabil. 2019;10:1-12. doi:10.2147/SAR.S183252.

6. Hooks C. Paranoid or persecuted? The stigmatisation of pregnant drug users: a literature review. Pr Midwife. 2015;Jan;18(1):14-8. PMID:26310087. doi: 10.2147/SAR.S183252

7. Frazer Z, McConnell K, Jansson LM. Treatment for substance use disorders in pregnant women: Motivators and barriers. Drug Alcohol Depend. 2019;205(107652). doi:

10.1016/j.drugalcdep.2019.107652. 
8. Nieweglowski K, Dubke R, Mulfinger N, Sheehan L, Corrigan PW. Understanding the factor structure of the public stigma of substance use disorder. Addict Res Theory. 2019;27(2):156-61; doi.org/10.1080/16066359.2017.1409890.

9. National Academies of Sciences E. Ending discrimination against people with mental and substance use disorders: the evidence for stigma change. Washington, District of Columbia: The National Academies Press; 2016.

10. van Boekel LC, Brouwers EPM, van Weeghel J, Garretsen HFL. Stigma among health professionals towards patients with substance use disorders and its consequences for healthcare delivery: systematic review. Drug Alcohol Depend. 2013;131(1-2):23-35. doi:

10.1016/j.drugalcdep.2013.02.018.

11. Avery JD, Taylor KE, Kast KA, Kattan J, Gordon-Elliot J, Mauer E, et al. Attitudes Toward Individuals With Mental Illness and Substance Use Disorders Among Resident Physicians. Prim Care Companion CNS Disord. 2019;21(1). doi: 10.4088/pcc.18m02382.

12. Sutter MB, Gopman S, Leeman L. Patient-centered Care to Address Barriers for Pregnant Women with Opioid Dependence. Obstet Gynecol Clin North Am. 2017;44(1):95-107. doi: 10.1016/j.ogc.2016.11.004.

13. Schempf AH, Strobino DM. Drug use and limited prenatal care: an examination of responsible barriers. Am J Obstet Gynecol. 2009;200(4):412.e1-10. doi: 10.1016/j.ajog.2008.10.055

14. American College of Obstetricians and Gynecologists Committee on Health Care for Underserved Women. AGOG Committee Opinion No. 473: substance abuse reporting and pregnancy: the role of the obstetrician-gynecologist. Obstet Gynecol. 2011;117(1):200-1. doi: 10.1097/AOG.0b013e31820a6216.

15. Avery J, Knoepflmacher D, Mauer E, Kast KA, Greiner M, Avery J, et al. Improvement in Residents' Attitudes Toward Individuals with Substance Use Disorders Following an Online Training Module on Stigma. HSS J Musculoskelet J Hosp Spec Surg. 2019;15(1):31-6. doi: 10.1007/s11420018-9643-3. 
16. Brief Substance Abuse Attitude Survey:

https://medicine.yale.edu/sbirt/curriculum/modules/medicine/brief_substance_abuse_attitude_survey_ 100733_284_13474_v1.pdf. Accessed 22 Nov 2018.

17. Chappel JN, Veach TL, Krug RS. The substance abuse attitude survey: an instrument for measuring attitudes. J Stud Alcohol. 1985;46(1):48-52. doi: 10.15288/jsa.1985.46.48

18. Ketterer F, Symons L, Lambrechts M-C, Mairiaux P, Godderis L, Peremans L, et al. What factors determine Belgian general practitioners' approaches to detecting and managing substance abuse? A qualitative study based on the I-Change Model. BMC Fam Pract. 2014;15:119. doi: 10.1186/1471-2296-15-119.

19. Hoffman A. L'accompagnement des usagers de drogues par les Médecins généralistes. 15 ans après...Santé conjugué n46. Fédérations des Maisons Médicales. 2008; 46.

20. Foster JH, Onyeukwu C. The attitudes of forensic nurses to substance using service users. J Psychiatr Ment Health Nurs.2003;10(5):578-84. doi: 10.1046/j.1365-2850.2003.00663.x.

21. van Boekel LC, Brouwers EPM, van Weeghel J, Garretsen HFL. Healthcare professionals' regard towards working with patients with substance use disorders: comparison of primary care, general psychiatry and specialist addiction services. Drug Alcohol Depend. 2014;134:92-8. doi: 10.1016/j.drugalcdep.2013.09.012.

22. May JA, Warltier DC, Pagel PS. Attitudes of anesthesiologists about addiction and its treatment: a survey of Illinois and Wisconsin members of the American Society of Anesthesiologists. J Clin Anesth. juin 2002;14(4):284-9. doi: 10.1016/s0952-8180(02)00359-8.

23. Ware JE, Sherbourne CD. The MOS 36-item short-form health survey (SF-36). I. Conceptual framework and item selection. Med Care. 1992;30(6):473-83.

24. Abel EL, Kruger M. Physician attitudes concerning legal coercion of pregnant alcohol and drug abusers. Am J Obstet Gynecol. 2002;186(4):768-72. doi: 10.1067/mob.2002.122142 25. Goodyear K, Chavanne D. Sociodemographic Characteristics and the Stigmatization of Prescription Opioid Addiction. J Addict Med. 2020;14(2):150-5. doi: 10.1097/ADM.0000000000000552. 
26. Goodman D, Whalen B, Hodder LC. It's Time to Support, Rather Than Punish, Pregnant Women With Substance Use Disorder. JAMA Netw Open Internet. 2019;(v 13;2(11):e1914135). doi:10.1001/jamanetworkopen.2019.14135.

27. Angelotta C, Weiss CJ, Angelotta JW, Friedman RA. A Moral or Medical Problem? The Relationship between Legal Penalties and Treatment Practices for Opioid Use Disorders in Pregnant Women. Womens Health Issues Off Publ Jacobs Inst Womens Health. 2016;26(6):595-601. doi: 10.1016/j.whi.2016.09.002.

28. Faherty LJ, Kranz AM, Russell-Fritch J, Patrick SW, Cantor J, Stein BD. Association of Punitive and Reporting State Policies Related to Substance Use in Pregnancy With Rates of Neonatal Abstinence Syndrome. JAMA Netw Open. 2019;2(11):e1914078. 2019.

doi: 10.1001/jamanetworkopen.2019.14078.

29. Brown SA. Standardized measures for substance use stigma. Drug Alcohol Depend. 2011;116(1-3):137-41. doi: 10.1016/j.drugalcdep.2010.12.005.

30. Gonzalez M, Clarke DE, Pereira A, Boyce-Gaudreau K, Waldman C, Demczuk L, et al. The impact of educational interventions on attitudes of emergency department staff towards patients with substance-related presentations: a quantitative systematic review. JBI Database Syst Rev Implement Rep. 2017;15(8):2153-81. doi: 10.11124/JBISRIR-2016-003006.

31. Mendiola CK, Galetto G, Fingerhood M. An Exploration of Emergency Physicians' Attitudes Toward Patients With Substance Use Disorder. J Addict Med. 2018;12(2):132-5. doi: 10.1097/ADM.0000000000000377.

32. Livingston JD, Milne T, Fang ML, Amari E. The effectiveness of interventions for reducing stigma related to substance use disorders: a systematic review. Addict Abingdon Engl. 2012;107(1):39-50. doi:10.1111/j.1360-0443.2011.03601.x.

33. Ayu AP, Schellekens AFA, Iskandar S, Pinxten L, De Jong CAJ. Effectiveness and Organization of Addiction Medicine Training Across the Globe. Eur Addict Res. 2015;21(5):223-39. doi: 10.1159/000381671. 
34. Ramirez-Cacho WA, Strickland L, Beraun C, Meng C, Rayburn WF. Medical students' attitudes toward pregnant women with substance use disorders. Am J Obstet Gynecol. 2007;196(1):86.e1-5. doi: 10.1016/j.ajog.2006.06.092.

35. Albright B, Skipper B, Riley S, Wilhelm P, Rayburn WF. Medical students' comfort with pregnant women with substance-use disorders: a randomized educational study. Acad Psychiatry J Am Assoc Dir Psychiatr Resid Train Assoc Acad Psychiatry. 2012;36(6):457-60. doi: 10.1176/appi.ap.11070134.

36. ACOG Committee on Health Care for Underserved Women, American Society of Addiction Medicine. ACOG Committee Opinion No. 524: Opioid abuse, dependence, and addiction in pregnancy. Obstet Gynecol. 2012;119(5):1070-6. doi: 10.1097/AOG.0b013e318256496e.

37. Brulet C, Chanal C, Ravel P, Mazurier E, Boulot P, Faucherre V. [Multidisciplinary monitoring and psychosocial support reduce complications of opiate dependence in pregnant women: 114 pregnancies]. Presse Medicale Paris Fr 1983. 2007;36(11 Pt 1):1571-80. doi: 10.1016/j.lpm.2007.05.017. 


\section{Figures}

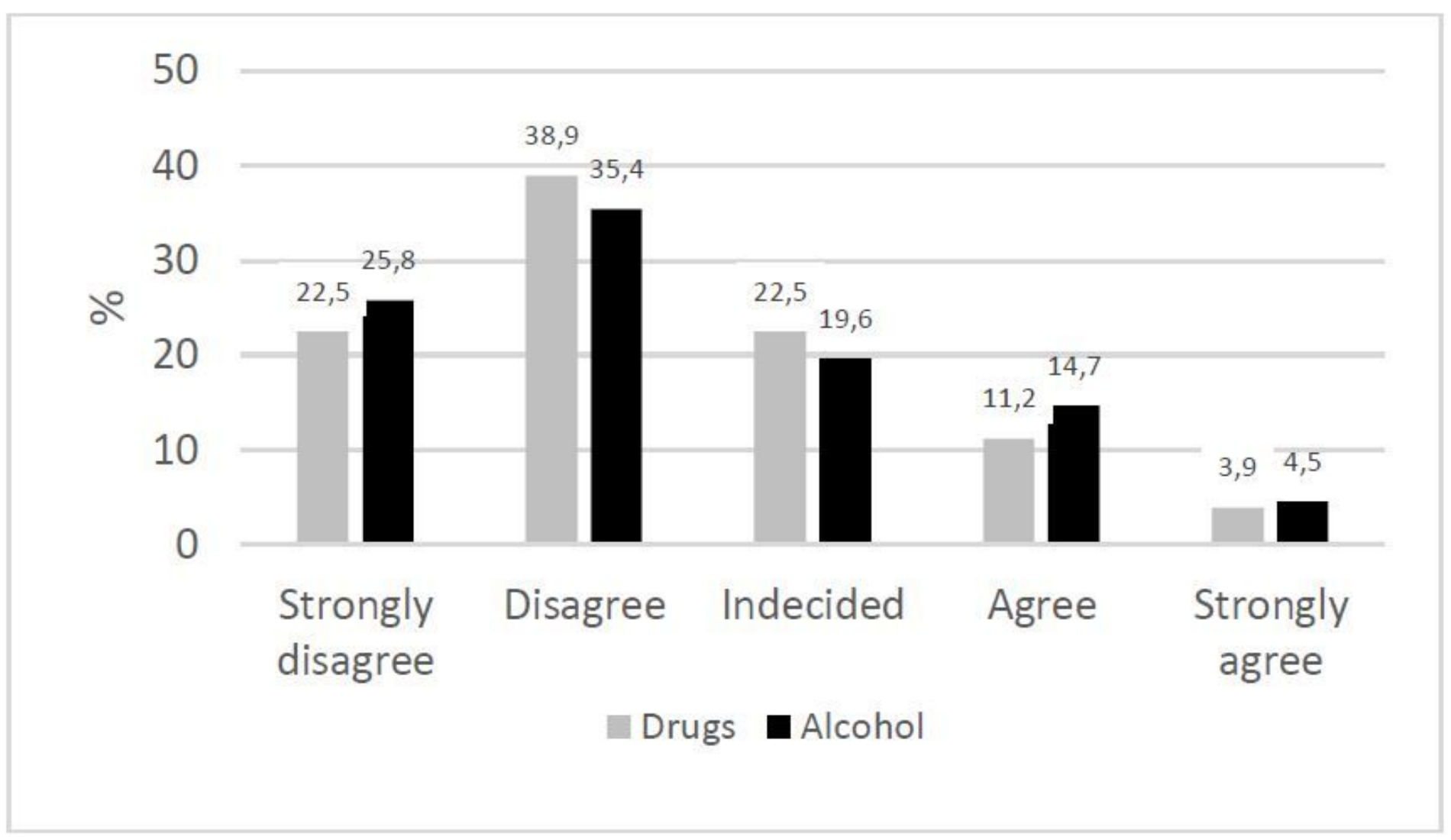

Figure 1

"Please see the Manuscript PDF file for the complete figure caption".
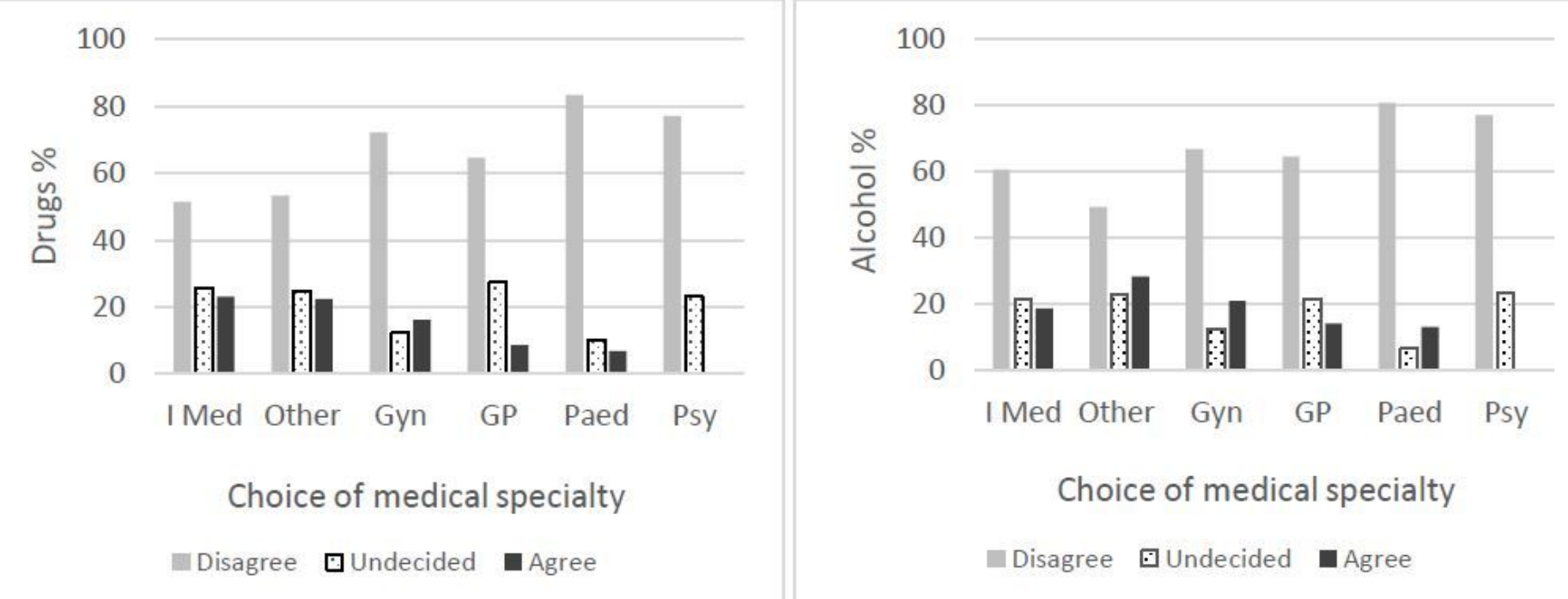

Figure 2

"Please see the Manuscript PDF file for the complete figure caption". 

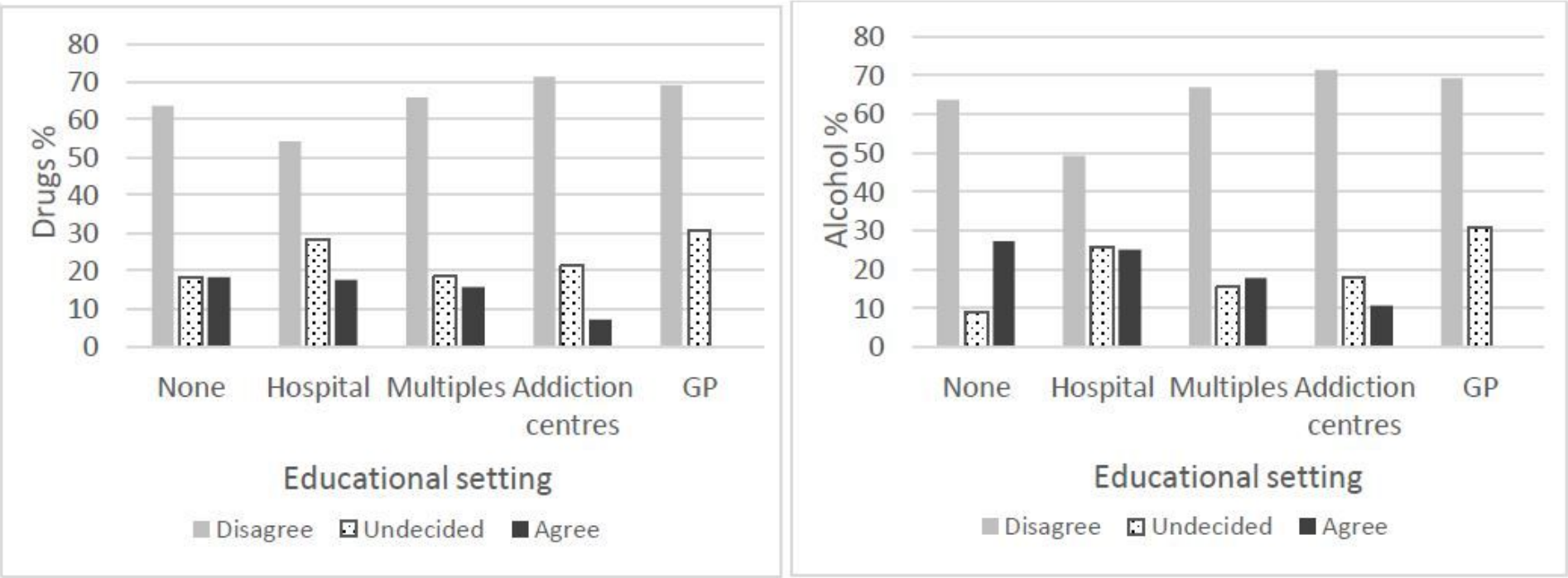

Figure 3

"Please see the Manuscript PDF file for the complete figure caption".

\section{Supplementary Files}

This is a list of supplementary files associated with this preprint. Click to download.

- SupplementaryMaterial.BMME.pdf 